PROCEDIA

Studi Kasus dan Intervensi Psikologi

ISSN:2302-1462

Volume 6(2) 54-58, Juli 2018

DOI: 10.22219 /procedia.v6i2.12642

\title{
Cognitive therapy untuk mereduksi kecemasan kecemasan pada orang dewasa
}

Nur Andini Sudirman, Universitas Muhammadiyah Malang, Malang, Indonesia

Korespondonesi:

Nur Andini Sudirman, Universitas Muhammadiyah Malang, Malang, eail: nurandini95@gmail.com

\author{
Riwayat artikel \\ Naskah diterima: \\ $02 / 03 / 2018$ \\ Revisi diterima: \\ $22 / 05 / 2018$ \\ Naskah disetujui: \\ $12 / 06 / 2018$
}

\begin{abstract}
Abstrak
SL (P/66 Tahun) subjek telah pensiun dari sekolah di Malang. Asesmen yang dilakukan adalah wawancara, observasi, grafis (DAP, BAUM, dan HTP), WAIS, dan skala BAI. Dari hasil asesmen diketahui bahwa SL mengalami permasalahan kecemasan yang disebabkan oleh adanya distorsi kognitif.Kecemasan SL berasal dari tensi yang tinggi sehingga membuat SL khawatir terkena stroke.Intervensi yang digunakan untuk menangani permasalah SL ialah terapi kognitif. Proses terapi menggunakan 6 sesi dengan target subjek dapat mengubah distorsi kognitif untuk mereduksi kecemasan. Hasi intervensi menunjukkan bahwa subjek mampu mengubah distorsi kognitifnya menjadi lebih positif sehingga dapat mereduksi kecemasannya.
\end{abstract}

Kata kunci:kecemasan, terapi kognitif

\section{Latar Belakang}

Kecemasan merupakan kondisi emosi yang samar dan tidak menyenangkan disertai dengan ciri-ciri takut pada sesuatu hal, menekan, dan tidak nyaman. Kecemasan biasanya dibedakan dari fear karena terkadang terarah kepada hal yang tidak berobjek, sedangkan rasa takut selalu mengarah kepada suatu objek, individu atau kejadian spesifik (Reber \& Reber, 2010). Dampak dari kecemasan pada lansia adalah memiliki kualitas tidur yang buruk dan penyesuaian diri yang buruk, seperti pada hasil penelitian menggunakan 66 orang lansia menunjukan bahwa terdapat hubungan antara tingkat kecemasan dan kualitas tidur lansia.Semua subjek memiliki kecemasan, $60 \%$ mengalami kecemasan sedang. Selain itu $45 \%$ mengalami kualitas tidur yang baik dan $55 \%$ mengalami kualitas tidur yang buruk (Dariah \& Okatiranti, 2015). Semakin tinggi tingkat kecemasan yang dimiliki oleh lansia, maka penyesuaian dirinya akan semakin buruk (Romas, 2010).

Faktor kecemasan yaitu psikologis, biologis, kesehatan, dan lainnya.Kecemasan berasal dari faktor psikologis seperi kognitif dan perilaku. Individu terkadang melebih-lebihkan apa yang ada 
dipikirannya sehingga dapat membuatnya takut dan menjadi cemas. Teori kognitif menjelaskan bahwa ketakutan individu dapat dikurangi saat ia mengalami hal yang mereka takuti, sehingga memungkinkan ia untuk melihat bahwa hal yang dipikirkan tidak berbahaya atau tidak seperti yang ia yakini (Rector, Bourdeau, Kitchen, \& Joseph-Massiah, 2008).

Permasalahan yang terjadi ialah subjek mengalami kecemasan yang ditandai dengan rasa khawatir, gelisah, dan mudah marah.Perasaan yang dialami subjek disebabkan oleh distorsi kognitif.Terapi yang dapat digunakan untuk individu yang mengalami kecemasan yaitu terapi kognitif.Cognitive therapy terbukti efektif untuk menangani kecemasan individu daripada menggunakan obat plasebo (Hofmann, Asnaani, Vonk, Sawyer, \& Fang, 2012).

\section{Metode Asesmen}

Asesmen untuk penegakan diganosa yang tepat dilakukan melalui serangkaian metode antara lain wawancara, observasi dan tes psikologi. Wawancara dilakukan terhadap subjek dan juga keluarga untuk memperoleh informasi lebih mendalam tentang permasalahan yang subjek alami.Observasi dilakukan untuk mengetahui kondisi dan perilaku subjek.

Tes psikologis yang digunakan mencakup tes kepribadian yaitu tes grafis (BAUM, DAP dan HTP) diperlukan untuk mengetahui kepribadian klien secara lebih mendalam. Selain itu tes Wechsler Adult Intelligence Scale (WAIS) dilakukan untuk mengetahui kemampuan subjek dalam berpikir dan memecahkan masalah.Selain itu subjek juga diberikan skala Beck Anxiety Inventory untuk melihat tingkat kecemasan subjek dan gejala-gejala yang subjek rasakan.

\section{Presentasi Kasus}

Subjek merupakan seorang wanita yang berusia 66 tahun.Subjek tinggal bersama satu orang anak, menantu, dan cucunya.Subjek telah bercerai dengan suaminya.Subjek merupakan anak terakhir dari 7 orang bersaudara.Subjek pensiuaan PNS disalah satu sekolah di Malang.

Subjek dirujuk oleh dokter karena hasil pemeriksaan medisnya tidak ditemukan masalah medis.Subjek mengaku bahwa sebelum ke puskesmas subjek sempat memeriksakan dirinya ke posiandu dekat rumahnya dan tensinya 140/100. Subjek menganggap bawa tensinya tinggi sehingga ia harus ke puskesmas untuk memeriksakan kembali kesehatannya. Subjek takut jika dibiarkan nanti subjek terkena stroke.Setelah diperiksa di puskesmas, subjek mengungkapkan bahwa tensinya masih tinggi.Padahal setelah di cek tensi subjek normal dengan hasil 120/70. Subjek berpikir bahwa jika dibiarkan tensinya tinggi, ia akan sakit. Subjek juga merasa takut dan khawatir saat mengetahui tensinya tinggi.Setelah mengetahui hal tersebut subjek hanya terus memikirkan kesehatannya.

Subjek mengemukakan bahwa sehari sebelum memeriksakan dirinya ke posiandu, subjek sempat berdebat dengan anaknya karena subjek khawatir dengan keputusan anaknya.Anaknya berhenti bekerja karena ingin menjadi pengusaha.Namun subjek berpikir bahwa jika anaknya berhenti bekerja, nanti anaknya tidak bisa sukses atau berpenghasilan tetap. Subjek terus memikirkan hal tersebut sehingga membuat subjek merasa khawatir dengan masa depan anaknya. Setelah subjek berdebat dengan anaknya, subjek selalu ingin mencurahkan ini hatinya.Namun subjek berpikir bahwa sudah tidak ada lagi yang bisa menjadi tempat curhatnya karena kakaknya telah meninggal.Subjek tidak tau harus curhat ke siapa karena semua saudaranya telah meninggal. Sehingga membuatnya untuk menyimpan masalahnya sendiri.

Subjek memiliki skor IQ 100 dengan kategori rata-rata.Subjek memiliki pengetahuan dan pengalaman yang luas, mampu berpikir abstrak, dan mampu menelaah masalah dengan baik, namun subjek kurang mampu dalam menangkap isi persoalan yang bersifat kompleks.Subjek memiliki kepribadian introvertseperti sensitif dan ragu-ragu. Subjek juga cenderung sulit mengutarakan perasaan dan pikiran kepada orang lain. Subjek mempunyai perasaan gelisah, 
cemas dan takut.Subjek sering merasa takut sakit dan khawatir nanti tidak ada yang merawatnya.

Subjek memiliki distorsi/pikiran negatif yang ditandai dengan adanya pikiran bahwa nanti tidak ada yang merawatnya jika sakit; nanti anaknya tidak bisa sukses atau berpenghasilan tetap saat menjadi wiraswasta; dan tidak ada lagi orang yang bisa menjadi tempat untuk mencurahkan isi hati subjek. Berdasarkan pikiran negative tersebut, jenis distorsi kognitif yang dimiliki subjek adalah catastrophizing ialah memprediksi masa depan secara negatif tanpa mempertimbangkan hasil lain yang lebih mungkin dan all-or-nothing thinkingyaitu individu melihat situasi hanya dalam dua kategori (Back, 2011).

Subjek selalu merasa takut sakit.subjek berpikir bahwa, jika ia sakit nanti tidak ada yang merawatnya. Jika subjek dan anaknya bermasalah juga mungkin anaknya tidak akan merawatnya. Subjek menjadi khawatir apabila ia sakit dan sekrat nanti tidak ada yang melihatnya meninggal. Saat subjek berada di rumah sakit atau puskesmas, subjek takut jika ia seperti orang-orang yang sedang berobat dirumah sakit. Dari distorsi kognitif yang dimiliki menyebabkan subjek memiliki perasaan khawatir, gelisah, tegang, mudah marah, dan sedih.Subjek selalu berdiam diri dikamar dan terkadang menangis.

Hasil tes beck anxiety inventory menunjukkan bahwa subjek memiliki kecemasan pada kategori kecemasan sedang dengan skor 22. Gejala yang subjek alami ialah adanya perasaan mudah marah, tidak relaks, takut, pusing, ragu-ragu, gelisah, jantung berdebar, dan takut akan mengalami kematian. Subjek selalu berupaya untuk menghilangkan pikiran negatif namun sulit untuk dihilangkan. Subjek merasa bahwa ia terlalu suka berpikir negatif subjek takut nanti tidak ada yang merawatnya saat sakit dan takut jika masa depan anaknya menjadi buruk. Saat pikiran tersebut muncul, subjek merasa khawatir, degdekan, tegang, dan gelisah.Dari pikiran tersebut subjek menjadi bingung dan akhirnya subjek berdiam diri dikamar.

Pendekatan yang dapat digunakan dalam masalah subjek ialah pendekatan kognitif.Back menjelaskan bahwa individu yang mengalami kecemasan memiliki pemikiran negatif yang mengakibatkan terjadinya berbagai emosi yang dirasakan (Back, 2011).Berdasarkan permasalahan tersebut maka intervensi yang cocok untuk mengatasi permasalahan subjek ialah terapi kognitif.Terapi kognitif terbukti dapat menurunkan kecemasan (Borkovec, Newman, \& Castonguay, 2003).

\section{Diagnosis dan Prognosis}

\section{Diagnosis}

Berdasarkan hasil pemeriksaan yang telah dilakukan, hasil diagnosis hampir memenuhi semua gejala dari diagnostic and statistical manual of mental disorder fifth edition (DSM-V) (APA, 2013).Subjek mengalami masalah kecemasan umum 300.02 (F41.1).Gejala yang dialami subjek ialah adanya distorsi kognitif yang menimbulkan perasaan takut, khawatir gejala berlangsung selama 1 tahun; dan saat 6 bulan terakhir merasa gelisah atau tegang.Subjek merasa sulit untuk mengendalikan kekhawatirannya dengan selalu memunculkan distorsi kognitif yang ditandai dengan berpikir bahwa nanti tidak ada yang merawatnya jika sakit.Gejala yang dialami menyebabkan sakit kepala.Hasil pemeriksaan medis tidak ditemukan masalah.

\section{Prognosis}

Prognosis positif karena kesadaran subjek terhadap kesehatan baik.Adanya motivasi untuk berubah menjadi lebih baik.Terdapat dukungan keluarga dalam membantu subjek unutk berpikir lebih positif.Tetangga subjek mengajak subjek untuk melakukan kegiatan positif seperti pengajian dan senam di puskesmas. 


\section{Intervensi}

Intervensi yang dilakukan pada permasalahan subjek yang mengalami kecemasan ialah terapi kognitif.Tujuan terapi ialah untuk membantu subjek mengidentifikasi pemikiran yang salah/ negatif.Alasan menggunakan terapi kognitif karena permasalahan subjek ialah adanya distorsi kognitif.Target intervensi yang dilakukan yaitu subjek menyadari pemikirannya yang salah/ negatif sehingga mampu mengubah distorsi kognitif untuk mereduksi kecemasan dalam waktu 1 minggu.

Terapi kognitif berfokus untuk membantu individu memecahkan masalah, mengidentifikasi, mengevaluasi, dan menanggapi pemikiran mereka yang tidak realistis dan maladaptif, terutama pemikiran negatif tentang diri sendiri, lingkungannya, dan masa depan (Back, 2011). Pemberian terapi kognitif terbukti efektif dapat menurunkan kecemasan (Tok, Arkar, \& Bildik, 2015). Terapi kognitif dapat membantu individu dalam mengubah pola berpikir yang maladaptif menjadi lebih positif (Seligman \& Ollendick, 2011).

Subjek mengidentifikasi pemikiran negatifnya yang telah menyebabkan emosi/perilaku bermasalah setelah itu akan dilakukan restrukturisasi kognitif. Teknik restrukturisasi kognitif bertujuan untuk mengidentifikasi pemikiran negatif yang sering muncul dan mengajari agar dapat menemukan pikiran alternatif yang lebih positif (Martin \& Pear, 2015). Restrukturisasi kognitif dilakukan dengan cara menentang pikiran negatif/ maladaptif sehingga subjek mampu berpikir positif. Proses intervensi dilakukan dalam 6 sesi sebagai berikut.

Sesi 1: Membangun raport dan self contracting. Pada sesi pertama terapis membangun raport dan membantu subjek mengidentifikasi masalah kekhawatirannya. Selanjutnya terapis dan subjek membangun komitmen agar bersungguh-sungguh dalam menjalani proses terapi yang akan ditargetkan. Terapis menjelaskan kepada subjek sesi-sesi yang akan dilakukan.

Sesi 2: Penetapan tujuan. Pada sesi kedua, terapis dan subjek menetapkan tujuan yang disepakati bersama untuk proses terapi. Subjek juga menyadari keuntungan dan kerugian apabila kecemasannya ditangani.

Sesi 3: Identifikasi pemikiran negatif. Pada sesi tiga, terapis membantu subjek untuk mengidentifikasi distorsi kognitifnya.Subjek menuliskan pikiran-pikiran yang dapat membuatnya khawatir. Distorsi kognitif yang ditemukan oleh subjek ialah (1) kalau sakit, nanti tidak ada yang merawat (catastrophizing), (2) anak nanti tidak dapat berpenghasilan tetap dan tidak bisa sukses (catastrophizing), (3) kehilangan orang sebagai tempat mencurahkan isi hati (all-or-nothing thinking).

Sesi 4: Restrukturisasi kognitif.Pada sesi empat terapis mengajari hubungan antara pikiran, perasaan, dan perilaku subjek. Terapis mengajak subjek untuk berpikir apa saja akibat dari distorsi/ pikiran negatifnya. Target sesi ini terpenuhi apabila subjek memahami dan menyadari bahwa pikiran negatifnya membuat ia menjadi cemas. Subjek menyadari bahwa apa yang ada dipikirannya itu salah.

Berdasarkan hasil restrukturisasi kognitif yang diperoleh, terapis mengajak subjek untuk berpikir positif.Terapis membantu subjek untuk menemukan sendiri pikiran positif.Sesi ini subjek menemukan pikiran positif seperti saya sehat, anaknya dapat menghasilkan uang, dan dapat mencurahkan perasaannya kepada orang terdekat.

Sesi 5: Evaluasi dan Terminasi. Pada sesi lima terapis mengevaluasi keseluruhan sesi yang telah dilakukan. Selanjutnya terapis melakukan pemberhentian terapi dan memberikan support agar subjek tetap berpikir positif. Evaluasi menunjukkan bahwa subjek dapat melakukan restrukturisasi kognitif sehingga dapat menurunkan kecemasan subjek.

Sesi 6: Follow up.Follow up dilakukan sebulan setelah intervensi. Terapis menanyakan tentang keadaan subjek setelah intervensi.Subjek mengaku bahwa tidak pernah lagi merasakan adanya 
kekhawatiran, takut, dan gelisah.Subjek juga mengaku tetap mempertahankan pemikiran positifnya.

\section{Hasil dan Pembahasan}

\section{Hasil}

Intervensi yang telah dilakukan menunjukkan hasil sesuai dengan target, yaitu subjek dapat mengubah distorsi kognitif untuk mereduksi kecemasan.Hal ini dapat terlihat dari distorsi kognitif subjek yang semakin berkurang dan bisa mengembangkan pikiran yang lebih positif.

Hasil intervensi membuat subjek menyadari bahwa distorsi/pikiran negatifnya seperti kalau sakit, nanti tidak ada yang merawat; anak nanti tidak dapat berpenghasilan tetap dan tidak bisa sukses; kehilangan orang sebagai tempat mencurahkan isi hati; dapat membuatnya menjadi khawatir, gelisah, dan sedih. Komitmen subjek saat terapi juga sangat baik dengan adanya usaha yang keras untuk mengembangkan pemikiran positifnya dan berpikir lebih rasional sehingga hal tersebut membuatnya lebih tenang dan bahagia. Gambar 1 merupakan hasil Skala Beck Anxiety Inventory yang menunjukkan adanya perubahan pemikiran subjek setelah intervensi.

Hasil evaluasi yang dilakukan 1 minggu setelah intervensi dengan menggunakan BAI menunjukkan bahwa kecemasan subjek berkurang dari kecemasan sedang (skor 22) menjadi normal (skor 5). Hasil follow up setelah 1 bulan menunjukkan bahwa subjek mampu mengubah pikirannya menjadi lebih positif. Subjek mengaku bahwa tidak pernah lagi merasakan adanya kekhawatiran, takut, dan gelisah.Subjek merasa lebih tenang dan bahagia.Subjek sudah rajin mengikuti kegiatan lansia di puskesmas.

\section{Pembahasan}

Pemberian intervensi dengan pendekatan terapi kognitif berhasil membuat subjek merubah distorsi kognitifnya menjadi positif hingga menurunkan kecemasan. Perubahan terlihat dari hasil pretest 22 dan postest 5 menunjukkan bahwa kecemasan yang dimiliki subjek menurun dari sedang ke normal. Hal tersebut ditandai dengan perasaan marah, tidak relaks, takut meninggal, dan ragu-ragu. Kategori BAI yaitu 0-7 poin normal, 8-15 poin kecemasan ringan, 16-25 poin kecemasan sedang, dan 26-63 poin kecemasan parah (Chen, dkk, 2009). Artinya subjek masih memiliki rasa cemas seperti orang lain pada umumnya, tetapi tidak begitu mengganggu.

Hasil identifikasi distorsi kognitif subjek antara lain nanti tidak ada yang merawat; anak nanti tidak dapat berpenghasilan tetap dan tidak bisa sukses; kehilangan orang sebagai tempat mencurahkan isi hati.Pemikiran tersebut muncul secara berulang dan menjadi keyakinan subjek

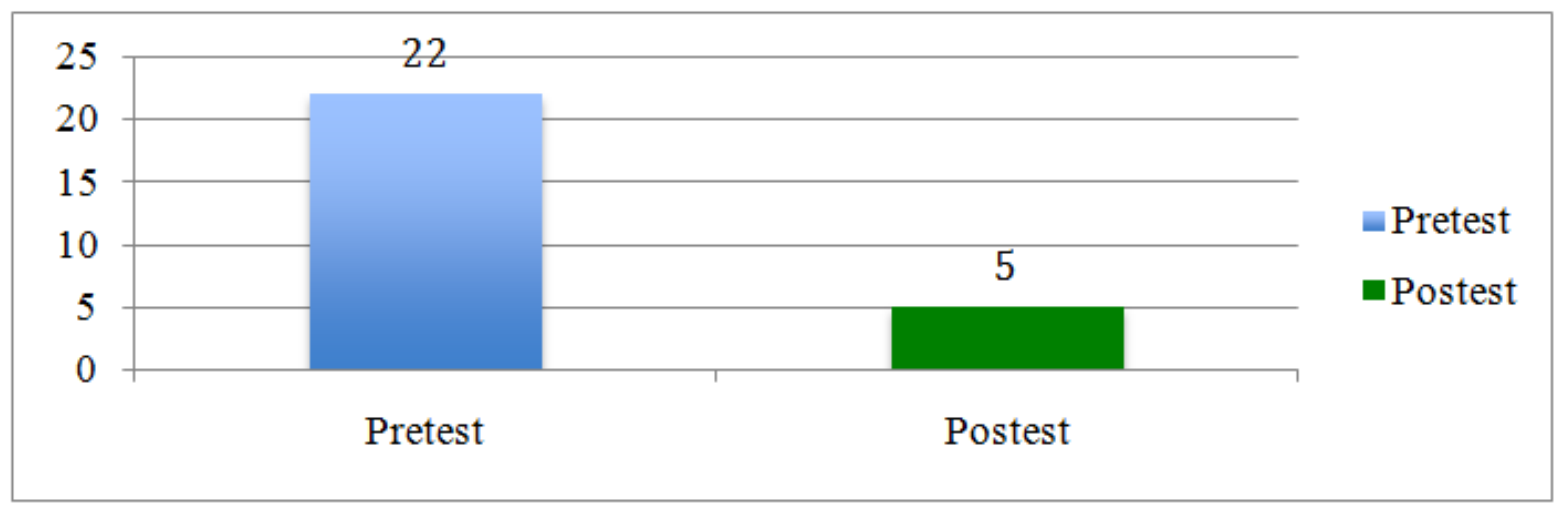

Gambar 1. Hasil Skala Beck Anxiety Inventory. 
sehingga memunculkan pemikiran negatif yang otomatis muncul dan diwujudkan melalui pikiran, perasaan dan perilaku (Putranto, 2016).

Jenis distorsi kognitif yang ditemukan pada subjek ialah catastrophizing, dan all-or-nothing thinking.Catastrophizing ialah pikiran yang memprediksi masa depan secara negatif tanpa mempertimbangkan hasil lain yang lebih mungkin. All-or-nothing thinking yaitu pikiran semua atau tidak sama skali yang melihat situasi hanya dalam dua kategori daripada dalam sebuah kontinum (Beck, 2011).

Subjek mampu menemukan pemikiran positif dengan mengidentifikasi pikiran-distorsi kognitif, sehingga subjek mampu mengubahnya. Ketika individu belajar untuk mengevaluasi pemikiran mereka dengan cara yang lebih realistis dan adaptif, mereka mengalami peningkatan dalam keadaan emosi dan perilaku mereka (Beck, 2011). Subjek merasa lebih bahagia dan tenang setelah memecahkan masalah yang dialaminya.

Dukungan dari keluarga membantu subjek menjadi lebih baik. Terlebih lagi subjek dirangkul oleh tetangganya agar mengikuti berbagai kegiatan seperti kajian-kajian islami dan senam bersama di puskesmas. Dukungan sosial dapat berasal dari keluarga, teman, guru, komunitas, atau kelompok sosial mana pun yang berafiliasi dengannya. Hasil penelitian menunjukkan bahwa semakin tinggi dukungan sosial yang diperoleh individu maka permasalahan psikologisnya semakin berkurang (Yasin \& Dzulkifli, 2010).

\section{Kesimpulan}

Cognitive Therapy dengan metode relaksasi dan restrukturisasi kognitif menunjukkan hasil yang baik dan sesuai dengan yang diharapkan.Jenis distorsi kognitif yang ditemukan pada subjek ialah catastrophizing, dan all-or-nothing thinking. Proses yang telah dilakukan dapat membuat subjek lebih berpikir positif. Subjek mampu mereduksi kecemasannya dengan cara mengubah distorsi/pikiran negatif menjadi positif.

\section{Referensi}

Anwar, Z. (2017). Intervensi Psikologi. Malang: UMM Press.

Beck, J. S. (2011). Cognitive Behavior Therapy Basic and Beyond second edition. London: The Guilford Press.

Chen, W. C., Chu, H., Lu, R. B., Chou, Y. H., Chen, C. H., Chang, Y. C., O'Brien, A. P., \& Chou, K. R. (2008). Efficacy of progressive muscle relaxation training in reducing anxiety in patients with acute schizophrenia. Journal of Clinical Nursing, 18 : 2187-2196.

Dariah, E. D., \& Okatiranti. (2015). Hubungan kecemasan dengan kualitas tidur lansia di posbindu anyelir kecamatan cisarua kabupaten bandung barat. Jurnal Ilmu Keperawatan, 3(2): 87-104.

Hofmann, S. G., Asnaani, A., Vonk, I. J. J., Sawyer, A. T., \& Fang, A. (2013). The efficacy of cognitive behavioral therapy: a review of meta- analyses, 36(5), 427-440. https://doi.org/10.1007/s10608-012-9476-1.

Martin, G., \& Pear, J. (2015).Modifikasi Perilaku Makna dan Penerapannya. Yogyakarta: Pustaka Pelajar.

Parnabas, V.A., Mahamood, Y., Parnabas, J., \& Abdullah, N.M. (2014).The relationship between relaxation techniques and sport performance.Journal of Psychology, 2(3), 108 - 112. DOI: 10.13189/ujp.2014.020302.

Putranto, A. K. (2016). Aplikasi Cognitive Behavior dan Behavior Activation dalam Intervensi Klinis.Jakarta : Grafindo.

Rector, A.N., Bourdeau, D., Kitchen, K., \& Joseph-Massiah, L. (2008).Anxiety Disorders: An Information Guide. Canada: CAMH.

Romas, M. (2010). Hubungan antara kecemasan dengan penyesuaian diri pada orang-orang lanjut usia. Journal of Psychology, 6(1): 1-10.

Tok, E. S. S., Arkar, H., \& Bildik, T. (2015). The effectiveness of cognitive behavioral therapy, medication, or combined treatment for childhood anxiety disorders. Journal of psyciatry, 1-8 doi: 10.5080/u13697. 